\title{
Zinc Oxide Nanoparticles in Bacterial Growth Medium: Optimized Dispersion and Growth Inhibition of Pseudomonas putida
}

\author{
Manuela Vielkind, Ingo Kampen, Arno Kwade \\ Institute for Particle Technology, Braunschweig University of Technology, Braunschweig, Germany \\ Email: m.vielkind@tu-bs.de
}

Received July 30, 2013; revised September 12, 2013; accepted September 30, 2013

Copyright (C) 2013 Manuela Vielkind et al. This is an open access article distributed under the Creative Commons Attribution License, which permits unrestricted use, distribution, and reproduction in any medium, provided the original work is properly cited.

\begin{abstract}
The majority of nanoparticles tend to agglomerate in bacterial growth media. Thus, nanoparticle-specific characteristics can get lost. To investigate the influence of nanoparticles on bacteria, these particles should remain in their nanoparticulate state. The present study demonstrates the stabilization of commercially available zinc oxide $(\mathrm{ZnO})$ with sodiumhexametaphosphate (SHMP) in bacterial growth medium (LB) to avoid agglomeration of these particles after the addition to LB. This established method is appropriate to stabilize $\mathrm{ZnO}$ agglomerates as small as $43 \mathrm{~nm}$. The method of fractionated centrifugation was used to obtain stable agglomerates (also stable in the presence of bacteria) with different mean diameters. The SHMP-stabilized $\mathrm{ZnO}$ inhibits the growth of Pseudomonas putida with increasing concentration (up to $500 \mathrm{mg} / \mathrm{L}$ ) and decreasing agglomerate size (43 - $450 \mathrm{~nm}$ ).
\end{abstract}

Keywords: Bacterial Growth Medium; Optimized Dispersion; Pseudomonas putida; Zinc Oxide Nanoparticles

\section{Introduction}

The dynamic development of nanotechnology has led to the increasing use of nanoparticles in convenience goods. Nanoparticles are used in the automotive, food, and cosmetic industries, as well as in medicine [1]. The small diameter of nanoparticles leads to a much higher surface-to-volume ratio compared with micro particles; consequently, a lot of possible applications arise, e.g. catalytically active materials, catalysts for exhaust emissions and nanoporose filters. Secondly, the decreasing diameter of nanoparticles leads to an increased invisibility of these particles in scratch-proof lacquers, self-cleaning surfaces, and cosmetics (especially sun blockers), as well as for antibacterial coatings in food packaging and textiles [2].

The annual production in Switzerland of metal oxide nanoparticles amounts from a few to several tons, which will still increase in the next years [3]. The increasing use of nanoparticles results in more of these engineered nanoparticles finding their way into the environment. Gottschalk et al. [4] predicted that nano- $\mathrm{ZnO}$ concentrations in sediment would be up to $6 \mu \mathrm{g} / \mathrm{kg}$ in 2012 in the US with this concentration showing an increasing ten- dency with time.

Regarding the behavior of these particles in the environment, two central questions arise: Do particles remain in their nanoparticulate state or do they congregate to coarse agglomerates/aggregates? Do substances such as humic acid that exist in the environment influence agglomeration behavior? In this study we assume that the particles maintain their nanoparticulate state, which we believe is the most critical condition.

The release of engineered nanoparticles into the environment leads to the contact of these particles with soil bacteria. This contact can result in inhibition of bacterial growth with the inhibitory effect increasing with decreasing agglomerate size [5-9]. The assessment of growth inhibition due to nanoparticle-specific characteristics of metal oxide nanoparticles requires the dispersion and stabilization of these particles in aqueous, $\mathrm{pH}$ neutral, ion- and protein-containing growth media such as lysogeny broth (LB) medium. Additionally, particles should be characterized suspended in the respective medium. Without particle stabilization, the composition of bacterial growth media leads to formation of micrometer-sized coarse agglomerates $(200-2000 \mathrm{~nm})$ with possible loss of nanoparticle-specific characteristics. This agglomera- 
tion phenomenon is observed in media for algae and animals [10-15]. To our knowledge, no study about the agglomeration behavior of $\mathrm{ZnO}$ nanoparticles in bacterial growth media, especially LB medium, has been published. Due to the wide use of LB media in bacterial growth tests, this medium was chosen for dispersion and stabilization studies to analyze nanoparticle-specific characteristics. The aim of our study was to stabilize zinc oxide $(\mathrm{ZnO})$ nanoparticles in order to avoid agglomeration after adding a $\mathrm{ZnO}$ suspension to $\mathrm{LB}$ ( $\mathrm{LB}=$ lysogeny broth, without sodium chloride $=$ salt-free LB). To achieve this goal two different stabilizers (sodiumhexametaphosphate (SHMP) and 2-[2-(2-methoxyethoxy) ethoxy] acetic acid (MEEAA)) were used. Sonication was used to disperse coarse agglomerates. The stabilizing ability of the abovementioned stabilizers was assessed in distilled water and salt-free LB by measuring particle size (by dynamic light scattering) and zeta potential (by microelectrophoresis). Dispersed and stabilized suspensions were centrifuged for various time intervals to separate larger agglomerates and achieve suspensions with different mean agglomerate sizes, down to $43 \mathrm{~nm}$. These suspensions were utilized to assess the nanoparticle-specific effects on growth of Pseudomonas putida. P. putida was selected because of its ubiquitous occurrence in the environment.

\section{Materials and Methods}

\subsection{Preparation and Characterization of $\mathrm{ZnO}$ Nanoparticles}

$\mathrm{ZnO}$ nanoparticles were available in dry, agglomerated form with a primary particle size of about $40 \mathrm{~nm}$. The powder was mixed with stabilizing agent (either sodiumhexametaphosphate (SHMP, $0.05 \mathrm{~g} / \mathrm{L}$ ) or 2-[2-(2methoxyethoxy) ethoxy] acetic acid (MEEAA, $0.2 \mathrm{~g} / \mathrm{L}$ )). The powder mixture was filled up with distilled water to a final concentration of $50 \mathrm{~g} / \mathrm{L} \mathrm{ZnO}$. The obtained suspension was dispersed using sonication with a specific energy input of $72 \mathrm{MJ} / \mathrm{kg}$. The sonicated dispersion was fractionated by centrifugation (differential centrifugation) to gain suspensions with different mean agglomerate sizes ( $1 \mathrm{~min}$ for $130 \mathrm{~nm}, 20 \mathrm{~min}$ for $43 \mathrm{~nm}$ ). The dry mass of each centrifuge effluent was determined by drying overnight $\left(100^{\circ} \mathrm{C}\right)$. Analysis of the agglomerate size distribution was carried out in a Zetasizer NanoZS (Malvern). This instrument determines the hydrodynamic diameter via dynamic light scattering. Each measurement consisted of at least 12 runs and was repeated 3 times.

Stability analysis in salt-free LB was carried out by diluting a $\mathrm{ZnO}$ suspension to approximately $5 \mathrm{~g} / \mathrm{L}$ with distilled water. This diluted suspension was given to salt-free LB to reach a final concentration of $500 \mathrm{mg} / \mathrm{L}$. After measuring agglomerate size distribution, suspen- sions were stored for at least seven hours. This corresponded to the duration of bacterial growth tests. Subsequently, the sizes of $\mathrm{ZnO}$ agglomerates were determined again to assess the stability of $\mathrm{ZnO}$ in salt-free $\mathrm{LB}$ during the cultivation period.

An additional important factor is the long-time term stability of nanoparticles. To consider this factor, agglomerate size distribution of SHMP- and MEEAA-stabilized $\mathrm{ZnO}$ was measured after storage times of up to 90 days.

\subsection{Zeta Potential Measurement}

The electrophoretic mobility of $\mathrm{ZnO}$ was determined using a Zetamaster S (Malvern Instruments). Unstabilized and stabilized (with SHMP and MEEAA) $\mathrm{ZnO}$ nanoparticles were diluted with distilled water and LB, respectively, to a final concentration of $100 \mathrm{mg} / \mathrm{L}$. The zeta potential was calculated from the mean of five measurements using the Smoluchowski equation [16].

\subsection{SEM-Image}

In order to visualize dispersing effects, SEM images of raw material and MEEAA- and SHMP-stabilized ZnO were prepared. This preparation comprised of centrifuging the samples $(13,000 \mathrm{rpm}$ for $20 \mathrm{~min})$, discarding the supernatant, drying the pellet overnight, and resuspending the pellet in ethanol. One drop of the obtained suspension was put on a glass slide. Samples were sputtered with gold to ensure electric conductivity.

\subsection{Microbiological Analysis}

SHMP-stabilized $\mathrm{ZnO}$ was studied with regard to growth inhibition of $P$. putida (DSM 50026, gram-negative, obtained from DSMZ, Braunschweig). To increase the confidence level growth tests were performed in 96-well plates. Each $\mathrm{ZnO} /$ stabilizer combination was measured nine-fold. With regard to stabilization of $\mathrm{ZnO}$ agglomerates, the LB media used contained no sodium chloride.

$\mathrm{ZnO}$ suspensions to be tested were diluted with distilled water in such a way that the ratio of $\mathrm{ZnO}$ suspension and salt-free LB was identical at any concentration. Tested doses $(0-500 \mathrm{mg} / \mathrm{L})$ were used to get an overview over a wide concentration range. Media was inoculated with an overnight culture $(10 \%)$ of $P$. putida and the 96-well plates were incubated on a special shaker $\left(30^{\circ} \mathrm{C}, 7 \mathrm{~h}\right)$.

Bacterial growth was determined hourly by measuring the optical density (OD) in the individual wells by means of the SUNRISE Absorbance Reader (TECAN, $600 \mathrm{~nm}$ ). The optical densities of the $\mathrm{ZnO}$ suspensions were subtracted as blank values from the respective measurements because $\mathrm{ZnO}$ suspensions exhibit an internal turbidity 
according to their concentration. Mean value and standard deviation were determined from nine parallel measurements for each concentration. Correlation between $\mathrm{OD}$ and bio dry mass $(\mathrm{BDM})$ is represented by

$$
\begin{aligned}
\mathrm{BDM}= & 0.00323+0.8424 \cdot \mathrm{OD} \\
& +0.10549 \cdot \mathrm{OD}^{2}+0.21024 \cdot \mathrm{OD}^{3}
\end{aligned}
$$

Maximum bacterial growth rate $\left(\mu_{\max }\right)$ was determined from the mean growth curves by estimating the slope of the exponential growth phase. Bacterial growth was calculated by division of $\mu_{\max }$ with respective $\mathrm{ZnO}$ concentrations and $\mu_{\max }$ without $\mathrm{ZnO}$.

\section{Results and Discussion}

\subsection{Stabilization of $\mathrm{ZnO}$}

Assessing the influence of nanoparticles on microorganisms requires interaction between the microorganisms and the particles in their nanoparticulate state. Industrially produced metal oxide nanoparticles tend to agglomerate in aqueous, $\mathrm{pH}$-neutral bacterial growth media containing ions and proteins [17-19]. The aim of this study was to establish a stabilization method for $\mathrm{ZnO}$ in salt-free LB in order to avoid agglomeration after adding the $\mathrm{ZnO}$ nanoparticles to bacterial growth media. The screening of potential stabilizers led to the exclusion of any $\mathrm{pH}$-shifting agents such as chloric acid or potassium hydroxide. Additionally, the stabilizing agent had to be nontoxic toward microorganisms. With regard to the aqueous media, no hydrophobic agent could be used.

The result of the screening led to sodiumhexametaphosphate (SHMP) and 2-[2-(2-Methoxyethoxy) ethoxy] acetic acid (MEEAA) being investigated with regard to their ability to stabilize $\mathrm{ZnO}$ in salt-free LB (Figure 1). These agents differ in their dispersion mechanism in that SHMP causes electrostatic stabilization, whereas MEEAA causes steric stabilization.

MEEAA-stabilized $\mathrm{ZnO}$ with sonication remained stable in distilled water over a period of at least seven hours (corresponding to the duration of the bacterial growth test). However, the addition of these particles to salt-free LB media led to immediate agglomeration with increasing $\mathrm{X}_{50}$ and increasing distribution width (Figure 2).

In contrast, the SHMP-stabilized and sonicated $\mathrm{ZnO}$ remained stable after addition to distilled water and salt-free LB. It should be noted that $\mathrm{ZnO}$ agglomerates were not completely dispersed and the measured $\mathrm{x}_{50}$ refers to agglomerates containing approx. three primary particles.

Optimized stabilizing methods of nanoparticles in bacterial growth media are one of the requirements for analyzing the inhibitory effects of nanoparticles to microorganisms.

The dispersion and stabilization effect of $\mathrm{ZnO}$ was visualized via SEM images (Figure 3). Before sonication

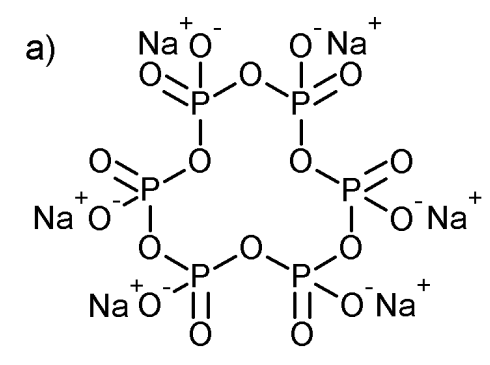<smiles>COCCOCCOCC(=O)O</smiles>

Figure 1. Chemical structure of SHMP (a) and MEEAA (b).

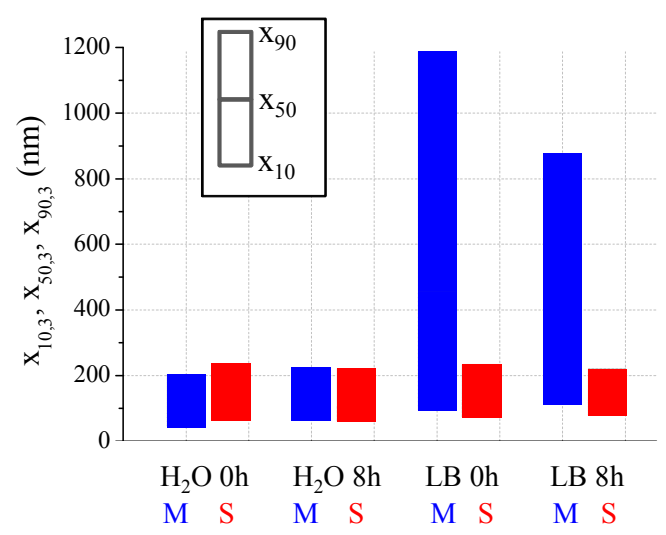

Figure 2. Agglomerate size of MEEAA (blue) and SHMP (red) stabilized $\mathrm{ZnO}$ in $\mathrm{H}_{2} \mathrm{O}$ and salt-free $\mathrm{LB}$. $\mathrm{ZnO}$ agglomerates (primary particle size approx. $40 \mathrm{~nm}$ ) were dispersed by sonication, stabilized, and the obtained suspension was centrifuged for $1 \mathrm{~min}$ to separate coarse agglomerates. To measure particle size distribution $\mathrm{ZnO}$ suspension was added to distilled water and salt-free $L B$ to reach a final concentration of $500 \mathrm{mg} \mathrm{ZnO} / \mathrm{L}$. The measurements were carried out directly after addition of suspension and after 8 hours storage.

the agglomerated powder was mixed with distilled water (Figure 3(a)). This mixture contained coarse agglomerates. These agglomerates were disrupted by sonication and the resulting smaller agglomerates and primary particles had to be stabilized. The comparison of Figures 3(b) and (c) supports the assumption that SHMP is a favorite stabilizer for this task because of the slightly higher amount of dispersed agglomerates. By means of SEM images, the centrifugation effect on the dispersed suspension can be explained as follows: With increasing duration of centrifugation an increasing amount of larger agglomerates are separated. Consequentially, the centrifuge effluent contains smaller agglomerates and primary particles and the concentration of solids decreases.

Physically stable dispersions are identified by maintaining their particle size distributions. The physical stability is a function of repulsive and attractive forces 

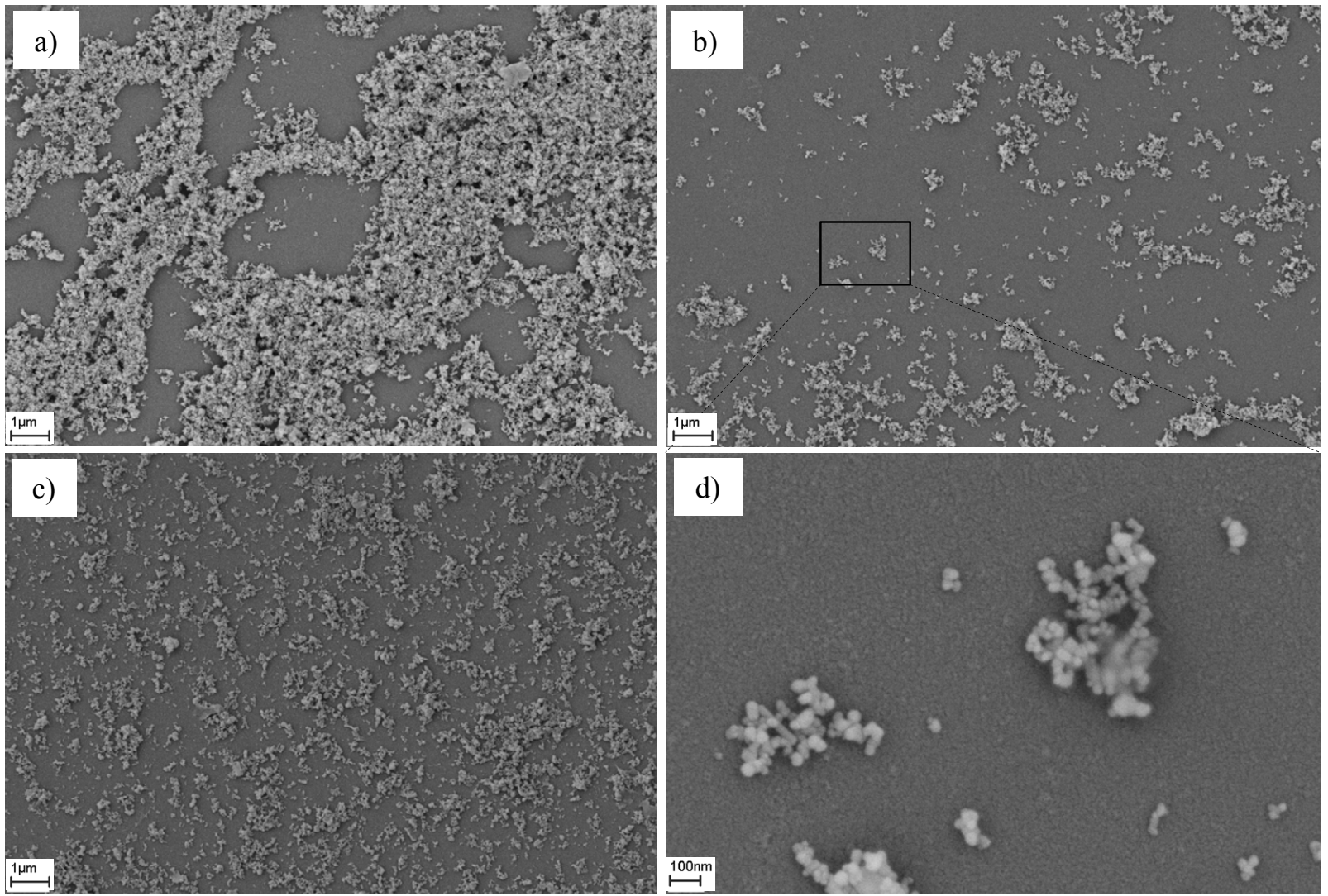

Figure 3. SEM images of $\mathrm{ZnO}$ agglomerates. a) $\mathrm{ZnO}$ powder mixed with $\mathrm{H}_{2} \mathrm{O}$; b) SHMP stabilized and sonicated $\mathrm{ZnO}$; c) MEEAA stabilized and sonicated ZnO, scale bar: 1 $\mathrm{m}$; c) MEEAA stabilized and sonicated ZnO; d) detail from b)

(DLVO (Derjaguin, Landau, Verwey, Overbeek) theory [20]).

Stabilizing agents were used to keep the particles at bay in order to avoid attraction and thereby agglomeration. The zeta potential is a value for the stability of dispersions [21]: high absolute value of zeta potential means high stability.

Different stabilizing methods (no stabilizer, SHMP and MEEAA) and the usage of sonication resulted in different agglomerate sizes and zeta potentials (Table 1).

Sonication led to smaller agglomerate sizes due to dispersion of coarse agglomerates. In the case of no stabilizer and MEEAA as stabilizer, the zeta potential of $\mathrm{ZnO}$ was positive and increased slightly through sonication. SHMP addition effected a charge conversion: unstabilized $\mathrm{ZnO}$ exhibited a positive zeta potential, whereas the zeta potential of SHMP stabilized $\mathrm{ZnO}$ was negative with nearly the same absolute value. Nearly all absolute values were located between 21 and $30 \mathrm{mV}$; this meant little agglomeration could occur [21]. Suganthi et al. [22] observed an increasing zeta potential of SHMP stabilized $\mathrm{ZnO}$ with increasing volume concentration. Their minimum tested concentration $(250 \mathrm{mg} / \mathrm{L})$ exhibited a zeta potential of $38 \mathrm{mV}$.

The similar high absolute zeta potential value of
SHMP-stabilized (negatively charged) and MEEAAstabilized (positively charged) $\mathrm{ZnO}$ do not cause similar stabilizing effect in salt free LB, although a high absolute value means high stability. In salt-free LB the zeta potential of all tested $\mathrm{ZnO}$ was about $-28 \mathrm{mV}$; this means all agglomerates had a negative surface charge, probably due to adsorption of LB components, mainly phosphate. Agglomeration of MEEAA-stabilized $\mathrm{ZnO}$ in salt-free LB (Figure 2) can be explained by time-delayed adsorption of LB components and associated surface charge reversal; already negatively charged particles attract to still positively charged particles and agglomeration occurs. SHMP-stabilized $\mathrm{ZnO}$ particles are a priori negatively charged, thereby repulsive forces predominate and agglomeration is avoided.

In consideration of reproducibility, long-term stability of the water-based suspension is favorable (Figure 4). SHMP-stabilized $\mathrm{ZnO}$-water suspension remained stable for at least three months, which enabled a high number of measurements based on the same charge of produced suspension.

MEEAA-stabilized $\mathrm{ZnO}$, however, showed a higher inconsistency in agglomeration states over this time period.

During cultivation of bacteria the media composition 
Table 1. Agglomerate size and zeta potential of different dispersion and stabilization methods. Particle size measurements were conducted three times (suspension concentration $5 \mathrm{~g} / \mathrm{L}$ in $\mathrm{H}_{2} \mathrm{O}, 500 \mathrm{mg} / \mathrm{L}$ in $\mathrm{LB}$ ), zeta potential measurements were conducted five times (suspension concentration $100 \mathrm{mg} / \mathrm{L}$ ); $\times_{50}$ values do not agree with those of Figure 2 because the suspensions here were extra produced for zeta potential measurements.

\begin{tabular}{cccccc}
\hline Stabilizer & Sonication & Media & Agglomerate Size $\times_{50.3}$ [nm] & Zeta Potential [mV] & pH \\
\hline No & No & $\mathrm{H}_{2} \mathrm{O}$ & $3403 \pm 1800$ & $20.6 \pm 2.3$ & $25.0 \pm 0.3$ \\
$\mathrm{No}$ & $\mathrm{Yes}$ & $\mathrm{H}_{2} \mathrm{O}$ & n.m. ${ }^{*}$ & $-28.2 \pm 0.6$ & 7.4 \\
$\mathrm{No}$ & $\mathrm{Yes}$ & $\mathrm{LB}$ & $2850 \pm 1760$ & $-26.9 \pm 0.5$ & 6.9 \\
SHMP & $\mathrm{No}$ & $\mathrm{H}_{2} \mathrm{O}$ & $433 \pm 79$ & $-26.9 \pm 0.6$ & 7.3 \\
SHMP & $\mathrm{Yes}$ & $\mathrm{H}_{2} \mathrm{O}$ & $147 \pm 10$ & $-27.9 \pm 0.9$ & 7.4 \\
SHMP & $\mathrm{Yes}$ & $\mathrm{LB}$ & $163 \pm 9$ & $25.6 \pm 0.3$ & 6.9 \\
MEEAA & $\mathrm{No}$ & $\mathrm{H}_{2} \mathrm{O}$ & $274 \pm 20$ & $28.6 \pm 0.3$ & 7.3 \\
MEEAA & $\mathrm{Yes}$ & $\mathrm{H}_{2} \mathrm{O}$ & $152 \pm 14$ & $-27.3 \pm 0.3$ & 7.3 \\
MEEAA & Yes & $\mathrm{LB}$ & $248 \pm 14$ & & 6.9 \\
\hline
\end{tabular}

"n.m.: not measurable.

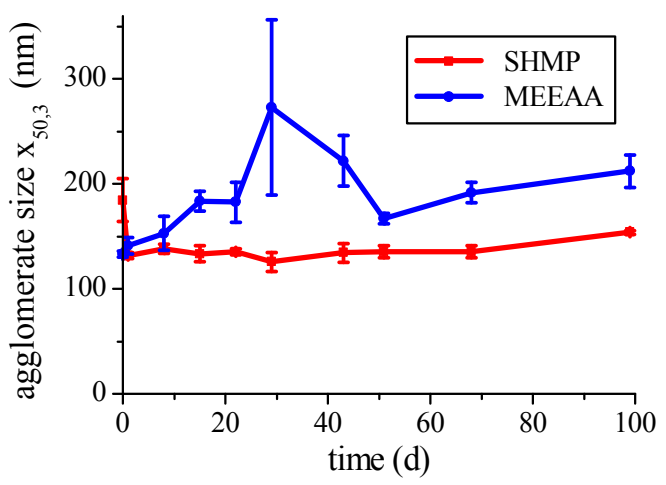

Figure 4. Long-term stability of SHMP- and MEEAA-stabilized ZnO dispersions. Particle size distribution was measured three times for each data point (suspension concentration approx. $3.5 \mathrm{~g} / \mathrm{L}$ ).

is altered through bacterial metabolism. Due to this fact, $\mathrm{ZnO}$ can agglomerate. To analyze this consideration particle size distribution was measured during cultivation experiments (Figure 5). Addition of $P$. putida cells led to a peak in the volume distribution in the range of three to six microns. This peak arose from the presence of bacterial cells; due to bacterial growth this peak increased with increasing cultivation period. The particle-to-cell proportion was possibly falsified due to differences in refractive indices of $\mathrm{ZnO}$ and bacterial cells. However, agglomeration of $\mathrm{ZnO}$ particles could not be completely excluded, but at least the amount of agglomerated particles was insignificant. To summarize, SHMP-stabilized $\mathrm{ZnO}$ was stable enough during cultivation to assess the nanoparticulate features.

Based on our knowledge no study exists about the agglomeration behavior and stabilizing methods of $\mathrm{ZnO}$ in LB media. Merely the observation of increasing agglom-

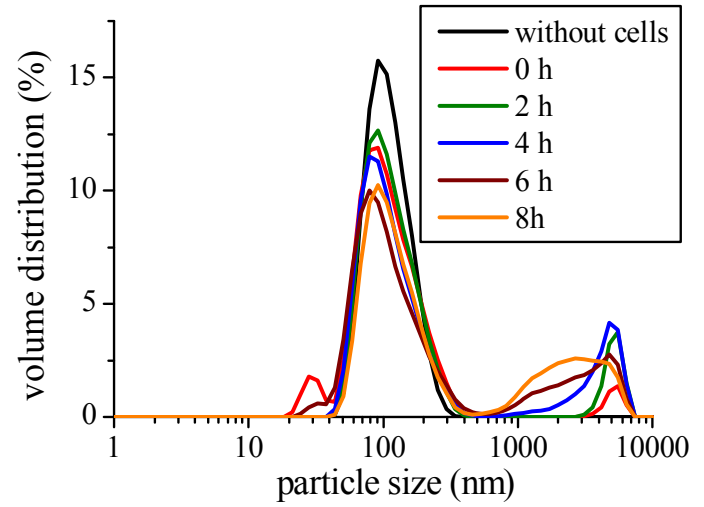

Figure 5. Volume distribution of SHMP-stabilized ZnO particles during cultivation of $P$. putida in salt-free LB. Particle size measurements were conducted three times per each time value in salt-free $\mathrm{LB}$ ( $\mathrm{ZnO}$ suspension concentration: $500 \mathrm{mg} / \mathrm{L}$ ).

erate size was observed by Li et al. [18] Other metal oxide nanoparticles such as titanium dioxide P25 (TiO2) were dispersed by Ji et al. [17] in LB media among other culture media. Addition of particles to all media led to immediate agglomeration. FBS (fetal bovine serum) was suitable to stabilize P25 in LB. However, the stabilizing effect refers to dispersion of $\mathrm{P} 25$ in $\mathrm{H}_{2} \mathrm{O}$, where agglomerate size is about $200 \mathrm{~nm}$ (primary size: $25 \mathrm{~nm}$ ). Compared to our study, no stabilized agglomerates smaller than $100 \mathrm{~nm}$ were obtained by Ji et al. in either water or LB.

\subsection{Agglomerate Size Dependent Influence of ZnO on Growth of $P$. putida.}

SHMP-stabilized $\mathrm{ZnO}$ was used to investigate the influence of nanoparticles on the growth of $P$. putida. $\mathrm{ZnO}$ 


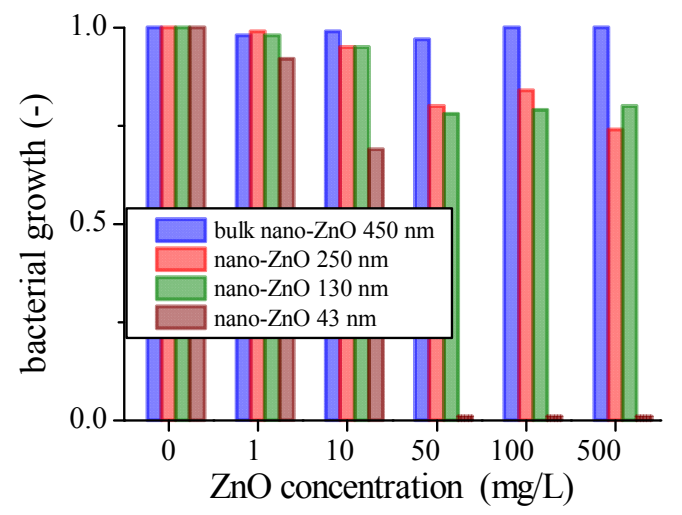

Figure 6. Growth of $P$. putida in the presence of SHMP containing $\mathrm{ZnO}$ according to agglomerate size and $\mathrm{ZnO}$ concentration. Bacterial growth (9-fold) was determined by estimating maximal growth rate from growth curves; obtained values were normalized to growth values without $\mathrm{ZnO}$ (0 $\mathrm{mg} / \mathrm{L} \mathrm{ZnO}$ ); indication of size was the respective $\times_{50}$-value; $43 \mathrm{~nm}$ particles were obtained by centrifugation of sonicated dispersions for $20 \mathrm{~min}$.

inhibited the growth of $P$. putida with decreasing agglomerate size and increasing concentration (Figure 6). Bulk nano- $\mathrm{ZnO}$ means the undispersed raw material, which was only mixed with SHMP and distilled water. Real nanosized agglomerates with $\times_{50}$ of $43 \mathrm{~nm}$ noticeably inhibited bacterial growth already at a concentration of $1 \mathrm{mg} / \mathrm{L}$, whereas coarser nanoparticle agglomerates needed a concentration $>10 \mathrm{mg} / \mathrm{L}$ for a clear influence on bacterial growth. Bulk nano- $\mathrm{ZnO}$ showed no toxic effects in the tested concentration range.

Growth inhibition of bacteria due to $\mathrm{ZnO}$ has been part of research for at least ten years. Former studies [5,6, $23,24]$ dispersed available nanoparticles (mostly primary particles, agglomerated in powder form) in water by stirring or sonication. Subsequently, bacterial inhibitory effects of these dispersions were analyzed without characterization of agglomerates in the bacterial growth media with respect to size and agglomerate state.

More recent studies [17] analyzed the agglomeration state of $\mathrm{ZnO}$ in LB media and detected coarse agglomerates. In the current study we not only detected the agglomeration, but also avoided it. The formation of coarse $\mathrm{ZnO}$ agglomerates in LB media as studied in literature complicates comparison of research results.

It is important to characterize agglomeration states of particles in test media prior to bacterial growth tests [25].

\section{Conclusion}

In this study we succeeded in the dispersion and stabilization of zinc oxide with different mean agglomerate sizes in bacterial growth media. The fractionated centrifugation resulted in stable agglomerates clearly below $100 \mathrm{~nm}$. Furthermore, the stabilized agglomerates re- mained stable during the bacterial cultivation period and, moreover, in the presence of bacteria as well. Thus, assessment of nanoparticle specific characteristics regarding growth inhibition of bacteria becomes possible. Investigating growth inhibition of $P$. putida in the presence of SHMP-stabilized $\mathrm{ZnO}$ resulted in increasing growth inhibition with decreasing agglomerate size. This growth inhibition could be explained by three possible mechanisms: production of increased amount of reactive oxygen species (ROS), interaction of nanoparticles with bacterial surface and associated disorganization and disruption of bacterial cell walls as well as increased release of zinc ions. The latter mechanism is the most likely one and object of future research.

\section{Acknowledgements}

We thank Peter Pfeiffer, Institute for Materials, TU Braunschweig, for preparing SEM-images and Christiane Schmidt, Institute of Environmental and Sustainable Chemistry, TU Braunschweig, for conducting ICP measurements.

\section{REFERENCES}

[1] "Project on Emerging Nanotechnologies," 2011. http://www.nanotechproject.org/inventories/consumer/

[2] Umweltbundesamt, Nanotechnik, "Chancen und Risiken für Mensch und Umwelt,” 2006.

http://www.nanotruck.de/fileadmin/user_upload/Berichte \%20und\%20Druckschriften/Literaturliste/Hintergrundpap ier_Umweltbundesamt.pdf

[3] K. Schmid and M. Riediker, "Use of Nanoparticles in Swiss Industry: A Targeted Survey," Environmental Science \& Technology, Vol. 42, No. 7, 2008, pp. 2253-2260. http://dx.doi.org/10.1021/es0718180

[4] F. Gottschalk, T. Sonderer, R. W. Scholz and B. Nowack, "Modeled Environmental Concentrations of Engineered Nanomaterials $\left(\mathrm{TiO}_{2}, \mathrm{ZnO}, \mathrm{Ag}, \mathrm{CNT}\right.$, Fullerenes) for Different Regions," Environmental Science \& Technology, Vol. 43, No. 24, 2009, pp. 9216-9222.

http://dx.doi.org/10.1021/es9015553

[5] L. Zhang, Y. Jiang, Y. Ding, M. Povey and D. York, "Investigation into the Antibacterial Behaviour of Suspensions of ZnO Nanoparticles (ZnO Nanofluids)," Journal of Nanoparticle Research, Vol. 9, No. 3, 2007, pp. 479489. http://dx.doi.org/10.1007/s11051-006-9150-1

[6] O. Yamamoto, "Influence of Particle Size on the Antibacterial Activity of Zinc Oxide," International Journal of Inorganic Materials, Vol. 3, No. 7, 2001, pp. 643-646. http://dx.doi.org/10.1016/S1466-6049(01)00197-0

[7] C. Gunawan, W. Y. Teoh, Ricardo, C. P. Marquis and R. Amal, "Zinc Oxide Nanoparticles Induce Cell Filamentation in Escherichia coli," Particle \& Particle Systems Characterization, Vol. 30, No. 4, 2013, pp. 375-380. http://dx.doi.org/10.1002/ppsc.201200152

[8] N. M. Franklin, N. J. Rogers, S. C. Apte, G. E. Batley, G. 
E. Gadd and P. S. Casey, "Comparative Toxicity of Nanoparticulate $\mathrm{ZnO}$, Bulk $\mathrm{ZnO}$, and $\mathrm{ZnCl} 2$ to a Freshwater Microalga (Pseudokirchneriella subcapitata): The Importance of Particle Solubility," Environmental Science \& Technology, Vol. 41, No. 24, 2007, pp. 8484-8490. http://dx.doi.org/10.1021/es071445r

[9] L. K. Adams, D. Y. Lyon and P. J. J. Alvarez, "Comparative Eco-Toxicity of Nanoscale $\mathrm{TiO}_{2}, \mathrm{SiO}_{2}$, and $\mathrm{ZnO}$ Water Suspensions," Water Research, Vol. 40, No. 19, 2006, pp. 3527-3532. http://dx.doi.org/10.1016/j.watres.2006.08.004

[10] P. Bihari, M. Vippola, S. Schultes, M. Praetner, A. G. Khandoga, C. A. Reichel, C. Coester, T. Tuomi, M. Rehberg and F. Krombach, "Optimized Dispersion of Nanoparticles for Biological in Vitro and in Vivo Studies," Particle and Fibre Toxicology, Vol. 5, 2008, p. 14. http://dx.doi.org/10.1186/1743-8977-5-14

[11] S. George, S. Pokhrel, T. Xia, B. Gilbert, Z. Ji, M. Schowalter, A. Rosenauer, R. Damoiseaux, K. A. Bradley, L. Mädler and A. L. Neal, "Use of a Rapid Cytotoxicity Screening Approach To Engineer a Safer Zinc Oxide Nanoparticle through Iron Doping," ACSNANO, Vol. 4, No. 1, 2010, pp. 15-28.

http://dx.doi.org/10.1021/nn901503q

[12] K. Hund-Rinke, K. Schlich and A. Wenzel, " $\mathrm{TiO}_{2}$ nanoparticles-Relationship between Dispersion Preparation Method and Ecotoxicity in the Algal Growth Test," Umweltwissenschaften und Schadstoff-Forschung, Vol. 22, No. 5, 2010, pp. 517-528. http://dx.doi.org/10.1007/s12302-010-0147-0

[13] A. A. Keller, H. Wang, D. Zhou, H. S. Lenihan, G. Cherr, B. J. Cardinale, R. J. Miller and Z. Ji, "Stability and Aggregation of Metal Oxide Nanoparticles in Natural Aqueous Matrices," Environmental Science \& Technology, Vol. 44, No. 6, 2010, pp. 1962-1967. http://dx.doi.org/10.1021/es902987d

[14] C. Schulze, A. Kroll, C.-M. Lehr, U. F. Schaefer, K. Becker, J. Schnekenburger, C. S. Isfort, R. Landsiedel and W. Wohlleben, "Not Ready to Use-Overcoming Pitfalls When Dispersing Nanoparticles in Physiological Media," Nanotoxicology, Vol. 2, No. 2, 2008, pp. 51-61. http://dx.doi.org/10.1080/17435390802018378

[15] T. Xia, M. Kovochich, M. Liong, L. Mädler, B. Gilbert, H. Shi, J. I. Yeh, J. I. Zink and A. E. Nel, "Comparison of the Mechanism of Toxicity of Zinc Oxide and Cerium Oxide Nanoparticles Based on Dissolution and Oxidative Stress Properties," ACSNANO, Vol. 2, No. 10, 2008, pp. 2121-2134. http://dx.doi.org/10.1021/nn800511k

[16] J. Lyklema, "Electrokinetics after Smoluchowski," Col- loids and Surfaces A: Physicochemical and Engineering Aspects, Vol. 222, No. 1-3, 2003, pp. 5-14. http://dx.doi.org/10.1016/S0927-7757(03)00217-6

[17] Z. Ji, X. Jin, S. George, T. Xia, H. Meng, X. Wang, E. Suarez, H. Zhang, E. M. V. Hoek, H. A. Godwin, A. E. Nel and J. I. Zink, "Dispersion and Stability Optimization of $\mathrm{TiO}_{2}$ Nanoparticles in Cell Culture Media," Environmental Science \& Technology, Vol. 44, No. 19, 2010, pp. 7309-7314. http://dx.doi.org/10.1021/es100417s

[18] M. Li, L. Zhu and D. Lin, "Toxicity of ZnO Nanoparticles to Escherichia coli: Mechanism and the Influence of Medium Components," Environmental Science \& Technology, Vol. 45, No. 5, 2011, pp. 1977-1983.

http://dx.doi.org/10.1021/es102624t

[19] D. N. Williams, S. H. Ehrman and T. R. P. Holoman, "Evaluation of the Microbial Growth Response to Inorganic Nanoparticles," Journal of Nanobiotechnology, Vol. 4, No. 3, 2006, pp. 1-8. http://dx.doi.org/10.1186/1477-3155-4-3

[20] E. J. W. Verwey and J. T. G. Overbeek, "Theory of the Stability of Lyophobic Colloids," Elsevier Pub. Co., New York, 1948.

[21] R. H. Müller, "Zeta Potential and Particle Charge in Laboratory Usage," Wissenschaftliche Verlagsgesellschaft, Stuttgart, 1996.

[22] K. S. Suganthi and K. S. Rajan, "Temperature Induced Changes in ZnO-Water Nanofluid: Zeta Potential, Size Distribution and Viscosity Profiles," International Journal of Heat and Mass Transfer, Vol. 55, 2012, pp. 79697980.

http://dx.doi.org/10.1016/j.ijheatmasstransfer.2012.08.03 $\underline{2}$

[23] R. Brayner, R. Ferrari-Iliou, N. Brivois, S. Djediat, M. F. Benedetti and F. Fiévet, "Toxicological Impact Studies Based on Escherichia coli Bacteria in Ultrafine $\mathrm{ZnO}$ Nanoparticles Colloidal Medium," Nano Letters, Vol. 6, No. 4, 2006, pp. 866-870. http://dx.doi.org/10.1021/n1052326h

[24] K. M. Reddy, K. Feris, J. Bell, D. G. Wingett, C. Hanley and A. Punnoose, "Selective Toxicity of Zinc Oxide Nanoparticles to Prokaryotic and Eukaryotic Systems," Applied Physics Letters, Vol. 90, No. 213902, 2007, pp. 213902-1-213902-3. http://dx.doi.org/10.1063/1.2742324

[25] M. Hasselöv, J. W. Readman, J. F. Ranville and K. Tiede, "Nanoparticle Analysis and Characterization Methodologies in Environmental Risk Assessment of Engineered Nanoparticles," Ecotoxicology, Vol. 17, No. 5, 2008, pp. 344-361. http://dx.doi.org/10.1007/s10646-008-0225-x 